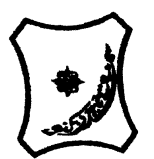

Bayero Journal of Pure and Applied Sciences, 10(1): 191 - 196

Received: March 2017

Accepted: June 2017

ISSN $2006-6996$

\title{
EFFECTS OF ETHYL ACETATE LEAF EXTRACTS OF Vitex simplicifolia ON ANTIOXIDANT VITAMINS, SOD, LIVER GLYCOGEN CONTENT AND LIPID PROFILE IN ALLOXAN INDUCED - DIABETIC WISTAR RATS
}

\author{
${ }^{*}$ Salim, M.A. ${ }^{1}$, Imam, A.A. ${ }^{2}$, Muhammad, S., Dikko, A.A.U. ${ }^{1}$, Tanko, Y. $^{3}$ and Mohammed, A. ${ }^{3}$ \\ ${ }^{1}$ Department of Human Physiology, Bayero University Kano \\ ${ }^{2}$ Department of Biochemistry, Bayero University Kano \\ ${ }^{3}$ Department of Human Physiology, Ahamadu Bello University, Zaria \\ *Corresponding author: zafaralisalimm@gmail.com, Phone: 08033265554
}

\begin{abstract}
The effects of oral administration of ethyl acetate leaf extract of Vitex simplicifolia on vitamins $A, E$ and $C$, Superoxide dismutase (SOD) and lipid profile levels in alloxan induced diabetic Wistar rats were investigated. The study was conducted with 30 Wistar rats, assigned into six groups of five rats each, and daily administration of ethyl acetate leaf extract of Vitex simplicifolia for 21 days was done. Diabetes mellitus was induced in overnight fasted rats by a single intraperitoneal injection (i.p) of $150 \mathrm{mg} / \mathrm{kg}$ body weight of alloxan monohydrate. Group 1 was the normal control group 2 was the diabetic control, group 3 was administered $10 \mathrm{mg} / \mathrm{kg}$ of glibenclimide (positive control) and groups 4, 5, and 6 were administered 250,500 and 1000mg/kg body weight of aqueous leaf extracts of Vitex simplicifolia respectively. There were no significant changes $(p<0.01)$ in the levels of total cholesterol (TC), triglycerol (TAG), low density lipoprotein cholesterol (LDL_c), high density lipoprotein -cholesterol (HDL $-c)$, SOD, vitamins $A_{\text {, }} E$ and $C$ for the animals administered with the extract compared with the control groups. The result of this study suggests that aqueous leaf extract of Vitex simplicifolia has no antioxidant and hypolipidemic effect.
\end{abstract}

Keywords: Vitex simplicifolia, SOD, Lipid Profile, Antioxidant Vitamins

\section{INTRODUCTION}

Diabetes is a major degenerative disease in the world today, affecting at least 150 million people and having complications which include hypertension, atherosclerosis and microcirculatory disorders (Ogbonnia et al., 2008). The prevalence of diabetes is on the increase globally and in African communities due to the ageing of the population and drastic lifestyle changes accompanying urbanization and westernization (Sobngwi et al., 2001). Also, studies from five West African communities in Nigeria and Ghana have identified genes within populations that create susceptibility to diabetes (Rotimi et al., 2010). The prevalence of diabetes mellitus in Nigeria is $1.9 \%$ with more than 1.5 million cases (IDF, 2015). Hence, it represents a growing burden on health care systems of African countries, most of which already face difficult economic conditions. The disease remains incurable and can only be controlled with drugs; hence, a scrupulous control is needed to help reduce hyperglycaemia and the risk of long-term complications, which are known to be the major causes of morbidity and mortality (Rotimi et al., 2010).

Oxidative stress plays a pivotal role in cellular injury from hyperglycemia. High glucose level can stimulate free radical production. Weak defense system of the body becomes unable to counteract the enhanced ROS generation and as a result, a condition of imbalance between ROS and their protection occurs which leads to domination of the condition of oxidative stress (Halliwell and Guttaridge, 2007). A certain amount of oxidative stress/ROS is necessary for the normal metabolic processes since ROS play various regulatory roles in cells (Gomes et al., 2015). Due to oxidative stress the metabolic abnormalities of diabetes cause mitochondrial superoxide overproduction in endothelial cells of both large and small vessels, as well as in the myocardium (Giacco and Browlee, 2010). Oxidative stress acts as mediator of insulin resistance and its progression to glucose intolerance and installation of diabetes mellitus, subsequently favouring the appearance of atherosclerotic complications, and contributes to rise in many micro- and macrovascular complications (Negre-Salvayre et al., 2009).

Antioxidant is a molecule that inhibits the oxidation of other molecules. It terminates chain reactions by removing free radical intermediates, and inhibits other oxidation reactions. Antioxidant defense mechanisms involve both enzymatic and non enzymatic strategies. Common antioxidants include the vitamins $A, C$, and $\mathrm{E}$, glutathione, and the enzymes superoxide dismutase (SOD), catalase, glutathione peroxidase, and glutathione reductase. Other antioxidants include lipoic acid, mixed carotenoids, coenzyme Q10, several bioflavonoid, antioxidant minerals (copper, zinc, manganese, and selenium), and the cofactors (Folic acid, Vitamins B1, B2, B6, B12). They work in synergy with each other and against different types of free radicals. 
Bajopas Volume 10 Number 1 June, 2017

Vitamin $E$ suppresses the propagation of lipid peroxidation; vitamin $\mathrm{C}$, with vitamin $\mathrm{E}$, inhibits hydrogen peroxide formation; metal complexing agents, such as penicillamine, bind transition metals involved in some reactions in lipid peroxidation (Feher et al., 1987) and inhibit Fenton and Haber-Weiss-type reactions; vitamins $A$ and $E$ scavenge free radicals (Baynes,1991). Extensive studies of pharmacological interventions based on biological antioxidants have been carried out (Oberley, 1988). Discrepancies in observed biomarkers for oxidative stress continue to be seen in the many review, especially in the activities of SOD, catalase, and glutathione peroxidase in experimentally induced diabetic animals.

In Nigeria, information available from the indigenous traditional healers indicates that, a decoction of the chopped stem barks and leaf of Vitex simplicifolia is prepared and taken orally for treatment of diabetes and other disease conditions. The plant extracts have been used as medication for infertility, liver disease, anodyne, stiffness, hypertension, cancer, febrifuge, as tonic galactagogue to aid milk production in lactating mothers, sedative, digestive regulator and treatment of eye, kidney and as supplement for lack of vitamin A and B (Sofowora, 1993; Burkill, 2000).

Although parts of this plant are used by traditional healers in the treatment of various ailments, there is paucity of scientific study to establish the scientific basis of its use and like many other herbal remedy, there is little or no information about its possible side effects or toxicities.

This study, therefore, was aimed at determining ' the hypolipidemic and antioxidant effects of ethyl acetate leaf extract of Vitex simplicifolia on alloxan induced diabetic Wistar rats.

\section{MATERIALS AND METHODS}

\section{Collection and Preparation of Plant Material}

Fresh leaves of Vitex simplicifolia were collected from the botanical garden of Bayero University, Kano with the assistance of Herbarium keeper. The leaves were authenticated in the Department of Biological Sciences, Bayero University Kano (Herbarium number 242). The leaves were dried under room temperature and then grounded using pestle and mortar to a semi powdered form.

\section{Experimental animals}

Thirty (42) adult Wistar rats weighing between 160 $240 \mathrm{~g}$ were obtained from the animal house of Department of Physiology, Bayero University, Kano and kept in cages at a room temperature for two (2) weeks to acclimatize and allowed access to food and water ad libitum.

\section{Plant extract}

Vitex simplicifolia leaves $(500 \mathrm{~g})$ were soaked in 2.5 litres of ethyl acetate at room temperature in a conical flask. The content of the flasks were shaken and the top was covered with aluminium foil and kept at room temperature for $48 \mathrm{~h}$ ( 2 days) after which the extracts were obtained by filtration using a Whatman No 1 filter paper. The extracts were concentrated using vacuum evaporator.

\section{Acute toxicity studies and determination of $\mathbf{L D}_{50}$}

The lethal dose was determined by Lorke's method.

Phase 1: Nine wistar rats were used. They were divided into three groups of three animals each. Each groups of animals were administered different doses $(10,100$, and $1000 \mathrm{mg} / \mathrm{kg})$ of the extracts and then observed for 24 hours to monitor their behavior as well as mortality.

Phase 2: Three animals were used. They were divided into three groups of one animal each. The animals were administered higher doses (1600, 2900 and $5000 \mathrm{mg} / \mathrm{kg}$ of the extracts and observed for behavior as well as mortality (Lorke, 1983)

Then $L D_{50}$ is calculated by the formula: $L D_{50}=\sqrt{ }$ $\left(D_{0} \times D_{100}\right)$

$\mathrm{D}_{0}=$ Highest dose that gave no mortality,

$D_{100}=$ Lowest dose that produce mortality .

Induction of diabetes mellitus

Diabetes mellitus was induced in overnight fasted rats by a single intraperitoneal injection (i.p) of $150 \mathrm{mg} / \mathrm{kg}$ body weight of Alloxan monohydrate (Etuk et al., 2010). Hyperglycaemia was confirmed by the elevated blood glucose levels, determined after $72 \mathrm{hrs}$ and then confirmed after $7^{\text {th }}$ day of injection. The rats found with elevated glucose level of $400 \mathrm{mg} / \mathrm{dl}$ and above were used for the study (Masiello et al., 1998).

\section{Experimental design}

A total of thirty (30) Wistar rats were used for the study. The rats were divided into Six (6) groups of five (5) each. Extracts were administered orally using $1 \mathrm{ml}$ syringe.

Group 1 - Normal untreated rats (Normal control)

Group 2 - Diabetic untreated rats (Negative control)

Group 3 - Diabetic rats administered $10 \mathrm{mg} / \mathrm{kg}$ of Glibenclamide (Positive control) (Prasanna et al., 2012)

Groups 4, 5 and 6 - Diabetic rats administered 250, 500 and $1000 \mathrm{mg} / \mathrm{kg}$ body weight of ethyl acetate leaf extract of Vitex Simplicifolia respectively.

Sub-chronic studies/ Collection and treatment of samples

The extracts were reconstituted in distilled water, and administered orally on daily basis for 21 days. At the end of 21 days, the animals were anaesthetized using chloroform and bled by cardiac puncture $24 \mathrm{hrs}$ after the last treatment. The blood samples were collected in specimen bottles, allowed clotting and the serum separated by centrifugation at 3000rpm for 10 minutes and then subjected to biochemical parameters analysis.

\section{Biochemical Analysis}

The serum levels of total cholesterol, triacylglycerol and $\mathrm{HDL}-\mathrm{C}$ were determined by enzymatic method as described by Stein (1987), while the serum levels of LDL-C was calculated by difference (Friedewald et al .,(1972). Liver glycogen was determined using the destruction by Alkali method (Good et al., 1933). Vitamins $A, C$ and $E$ were determined by the methods of Bessey et al., (1946), Roe and Kuether, (1943) and (1968) respectively, while SOD was determined using the method of Mc cord and Fridorich (1969).

\section{Phytochemical screening}

Test for anthraquinones was conducted using the method of Felgils (1975) and Test for alkaloids and Terpenes was carried out using the method of Sofowora (1979) while Test for saponins, flavonoids and tannins were done using the method of Earl (1961) 


\section{STATISTICAL ANALYSIS}

The results obtained are presented as Mean \pm standard error of mean (SEM). A one way analysis of variance (ANOVA) was used for the data analysis. Significant differences between groups were detected in the ANOVA using Bonferini test at $P$ values less than 0.05 and 0.001 , using SPSS 20 Soft ware package for windows.

RESULTS

Tables 1 and 2 below present the result of acute toxicity studies showing the $\mathrm{LD}_{50}$ of ethyl acetate extract of Vitex simplicifolia leaf is greater than 5000 $\mathrm{mg} / \mathrm{kg}$ body weight.

Table 1: Phase I LD

\begin{tabular}{lcll} 
Group & No. of Animals & Doses $(\mathrm{g} / \mathrm{Kg})$ & No. of Death \\
\hline 1 & 3 & 10 & 0 \\
2 & 3 & 100 & 0 \\
3 & 3 & 1000 & 0 \\
\hline
\end{tabular}

Table 2: Phase II LD 50 (Oral) of the ethyl acetate leaf extract of Vitex simplicifolia

\begin{tabular}{llll} 
Group & No. of Animals & Doses $(\mathrm{mg} / \mathrm{Kg})$ & No. of Death \\
\hline 1 & 1 & 1600 & 0 \\
2 & 1 & 2900 & 0 \\
3 & 1 & 5000 & 0 \\
\hline
\end{tabular}

Table 3: Results of phytochemical screening of the ethyl acetate extract of the Vitex simplicifolia leaf

\begin{tabular}{ll}
\hline Phytochemicals & Qualitative \\
\hline Alkaloids & Present \\
Cardiac glycosides & Present \\
Phenols & Absent \\
Flavonoids & Present \\
Saponins & Present \\
Tannins & Present \\
Steroids & Absent \\
Terpenoids & Absent \\
Phytates & Present \\
Oxalates & Present \\
Cyanates & Present \\
\hline
\end{tabular}

\section{Effects on lipid profile and Liver Glycogen content}

The effect of daily doses of ethyl acetate leaf extract of Vitex simplicifolia on lipid profile of alloxan induced diabetics rats is presented in Table 5.There was no significant $(p<0.05)$ changes in the serum level of total cholesterol(TC), trglyceride (TAG), low density lipoprotein cholesterol (LDL-C) and high density lipoprotein -Cholesterol (HDL-c) for the animals administered with the extract as compared with the control groups. The liver glycogen content was significantly lower $(p<0.05)$ in the diabetic control compared to the normal control and significantly higher in test groups compared to the control groups (Table 5).

Table 5: Effect of oral administration of ethyl acetate fraction of leaf extract of Vitex simplicifolia on liver glycogen content and lipid profile on alloxan induced diabetic rats.

\begin{tabular}{llllll}
\hline Groups & $\begin{array}{l}\text { Glycogen } \\
(\mathrm{mg} / \mathrm{g})\end{array}$ & $\begin{array}{l}\text { Total Chol } \\
(\mathrm{mmol} / \mathrm{l})\end{array}$ & $\begin{array}{l}\text { Triglyceride } \\
(\mathrm{mmol} / \mathrm{l})\end{array}$ & $\begin{array}{c}\mathrm{HDL} \\
(\mathrm{mmol} / \mathrm{l})\end{array}$ & $\begin{array}{c}\mathrm{LDL} \\
(\mathrm{mmol} / \mathrm{l})\end{array}$ \\
\hline & & & & & \\
1 & $3.28 \pm 0.09$ & $0.24 \pm 0.01$ & $0.12 \pm 0.05$ & $0.20 \pm 0.03$ & $0.02 \pm 0.03$ \\
2 & $1.96 \pm 0.24$ & $0.27 \pm 0.01$ & $0.11 \pm 0.03$ & $0.12 \pm 0.02$ & $0.10 \pm 0.01$ \\
3 & $2.88 \pm 0.02$ & $0.14 \pm 0.11$ & $0.08 \pm 0.03$ & $0.13 \pm 0.06$ & $0.07 \pm 0.04$ \\
4 & $1.91 \pm 0.34$ & $0.12 \pm 0.01$ & $0.06 \pm 0.012$ & $0.06 \pm 0.012$ & $0.21 \pm 0.02$ \\
5 & $2.10 \pm 0.10$ & $0.12 \pm 0 \mathrm{E}-7$ & $0.11 \pm 0.001$ & $0.04 \pm 0.01$ & $0.21 \pm 0.02$ \\
6 & $3.60 \pm 0.20^{\mathrm{b}}$ & $0.07 \pm 0.05$ & $0.13 \pm 0.04$ & $0.09 \pm 0.01$ & $0.23 \pm 0.02$ \\
\hline
\end{tabular}

Grp 1: Normal control, Grp 2: Negative control, Grp 3: Positive control, Grps 4, 5 and 6 received 250,500 and $1000 \mathrm{mg} / \mathrm{kg}$ of extract, respectively. Total chol $=$ Total cholesterol. Values are presented as mean \pm standard error of mean. ${ }^{b}=$ significantly different $(p<0.05)$ from the Negative control. 


\section{Effects on SOD and Antioxidant Vitamins}

The effect of daily doses of ethyl acetate leaf extract of Vitex simplicifolia on SOD and Vitamins $A, C$ and $E$ in alloxan induced diabetics rats is presented in Table 6. There was a significant decrease $(p<0.05)$ in vitamin $A$ and no significant $(p<0.05)$ change in superoxide dismutase (SOD), Vitamin $\mathrm{C}$ and $\mathrm{E}$ for the animals administered with the extract compared with the control groups.

Table 6: Effect of oral administration of ethyl acetate leaf extract of Vitex simplicifolia on the activity of SOD and levels of vitamins A, C, E on alloxan induced diabetic rats.

\begin{tabular}{lllll}
\hline Groups & $\begin{array}{l}\text { SOD } \\
(\mu \mathrm{mole} / \mathrm{min} / \mathrm{mg} \\
\text { protein }) \times 10^{5}\end{array}$ & $\begin{array}{l}\text { VIT-A } \\
(\mathrm{mg} / \mathrm{dl})\end{array}$ & $\begin{array}{l}\text { VIT-C } \\
(\mathrm{mg} / \mathrm{dl})\end{array}$ & $\begin{array}{l}\text { VIT-E } \\
(\mathrm{mg} / \mathrm{dl})\end{array}$ \\
\hline 1 & $1.57 \pm 0.28$ & $632.40 \pm 34.50$ & $0.53 \pm 0.24$ & $20.60 \pm 0.88$ \\
2 & $0.41 \pm 0.16$ & $499.67 \pm 113.92$ & $0.28 \pm 0.14$ & $22.69 \pm 1.73$ \\
3 & $0.44 \pm 0.32$ & $460.00 \pm 1.00$ & $0.92 \pm 0.79$ & $23.52 \pm 3.49$ \\
4 & $0.74 \pm 0.27$ & $144.67 \pm 19.88^{\mathrm{ab}}$ & $0.65 \pm 0.17$ & $24.12 \pm 1.10$ \\
5 & $0.80 \pm 0.20$ & $249.00 \pm 2.00^{\mathrm{a}}$ & $0.40 \pm 0.10$ & $26.40 \pm 1.10$ \\
6 & $0.90 \pm 0.40$ & $240.00 \pm 5.00^{\mathrm{a}}$ & $0.55 \pm 0.10$ & $20.60 \pm 0.88$ \\
\hline
\end{tabular}

Grp 1: Normal control, Grp 2: Negative control, Grp 3: Positive control, Grp 4, 5 and 6 received 250,500 and $1000 \mathrm{mg} / \mathrm{kg}$ of extract, respectively. Values are presented as mean \pm standard error of mean. ${ }^{\mathrm{a}}=$ significantly different $(p<0.05)$ from the Normal control, ${ }^{b}=$ significantly different $(p<0.05)$ from the Negative control, ${ }^{c}=$ significantly different $(p<0.05)$ from Positive control.

\section{DISCUSSION}

The result of acute toxicity study indicated that the $\mathrm{LD}_{50}$ of the ethyl acetate leaf extract of Vitex simplicifolia is greater than $5000 \mathrm{mg} / \mathrm{kg}$ body weight (Table 2). Thus, the non-lethal effects produced with the high dose of this extract are an indication that the leaf extracts of Vitex simplicifolia is relatively safe on acute oral exposure. It can therefore be concluded that Vitex simplicifolia leaf extract is non-toxic, which is in agreement with the report of Abdelmagid (2014) on essential oil of the leaves of Vitex simplicifolia and with Bruce (1987), American Society for Testing and Materials (1987), Aditya and Ravi (2014),Kingsley et al (2014) and Ravichandran et al (2014), that any chemical substance with $\mathrm{LD}_{50}$ estimate greater than $3000-5000 \mathrm{mg} / \mathrm{kg}$ (oral route) could be considered of low toxicity and safe.

In this study, the ethyl acetate leaf extracts of Vitex simplicifolia showed no significant effect on lipid profile of the experimental animals (Table 5). The aqueous extract of Vitex simplicifolia had no significant effect on the level of total cholesterol and low density lipoprotein. These observations may be attributed to the gut intra - luminal interactive effect of saponin. Saponins are known anti nutritional factors which reduce the uptake of certain nutrients including glucose and lipid especially cholesterol at the gut through intra-lumena physicochemical interaction. Hence saponins have been reported to have hypocholestrolemic effect (Price et al., 1987). Saponin, among other secondary metabolites is found to be present in the leaves of Vitex simplicifolia in this study (Table 3). The low concentration of cholesterol may have contributed to the observed non significant high serum HDL - cholesterol in the experimental animals. About $30 \%$ of blood cholesterol is carried in the form of $\mathrm{HDL}$ and it is hypothesized that HDL - cholesterol can remove cholesterol from antheroma within arteries and transport it back to the liver. HDL - cholesterol protect against cardiovascular disease (Okpe et al., 2012). The observed non - significant $(p<0.05)$ increase in $\mathrm{HDL}$ - cholesterol concentration after administration of the extracts (250, 500 and 1000 $\mathrm{mg} / \mathrm{kg} \mathrm{bw}$ ) indicates that the extract does not have $\mathrm{HDL}$ - cholesterol boosting effect and it does not also have significant $(p<0.05) \mathrm{LDL}$ - cholesterol lowering effect at these concentrations in induced diabetic experimental animals.

Oral administrations of ethyl acetate extract of Vitex simplicifolia for 21 days significantly increase $(p<0.05)$ liver glycogen content (Table 5 ). The liver glycogen content is significantly lower $(p<0.05)$ in the diabetic control compared to the normal control. This finding does not appear to be related to dietary conditions, since all experimental animals were fed the same type of feed. It is possible that diabetic subjects have defects in liver and muscle glycogen synthesis (Shulman et al, 1990). The increase in liver glycogen content is by possible reversal of the earlier mentioned (defects in liver and glycogen synthesis).

Oral administration of ethyl acetate leaf extract of Vitex simplicifolia in this study showed a significant decrease in vitamin $A$ and no significant $(p<0.05)$ change in superoxide dismutase (SOD), vitamin $\mathrm{C}$ and E (Table 6). 
Bajopas Volume 10 Number 1 June, 2017

A decrease in SOD and vitamin A is an indication of lack of antioxidant activity (Giugliano, 1995). Anti oxidant defense mechanism involves both enzymatic and non enzymatic strategies. Common antioxidants including vitamins $A, C$ and $E$ and superoxide dismutase etc work in synergy with each other to

\section{REFERENCES}

Abdel majid, O., Noya S, Jean K, Sylvin $\mathrm{O}$ and Innocent P G (2014).Acute toxicity and irritancy of the essential oil of the leaves of Vitex simplicifolia Oliv.(Verbenaceae) in Bourkinafaso, Journal of Pharmacology and Toxicology.9 (1):62-67

Abdulrahaman, F.I (1992).Studies in natural products chemistry. The moraceae in African traditional medicine and management of psychiatry in Borno State.M.Sc Thesis. University of Maiduguri.Maiduguri.

Aditya, K and Ravi,K (2014).Toxicity studies of combined extracts of Vitex pubescence, Vitex penducularis and Vitex agnucastus, Indian Journal of Research in Pharmacy and Biotechnology,2(2):1109 -1113

American Society for testing and Materials. (1987). Standard test method for estimating acute oral toxicity.OECD 425:1-8

Baynes J, (1991). Role of oxidative stress in development of complications in diabetes, Diabetes, 40(4): 405-412.

Bessey, 0. A. (1946) Journal of Biological Chemistry, 126, 771

Bruce, R.D (1987). A Confirmatory Study of up-anddown Method of Acute Oral Toxicity Testing. Fundamental Applied Toxicology. 8: 97-100.

Burkill, HM (2000). Useful Plants of Tropical West Africa.2nd ed.. Royal Botanic Garden Keiv. 272-275

Earl, J.K (1961) Chemical composition of plant tissues.Biochemists Handbook.Redwood Press London

Etuk E (2010).Animal models for studying diabetes mellitus. Agriculture and Biology Journal of North America. issn 2151-7517.http://www scihub.org/ABJNA.

Fabianek J, DeFilippi J, Rickards T and Herp A (1968). Micromethod for tocopherol determination in blood serum. Clin. Chem., 14(5): 456-462.

Feher J, Cosmos G and Vereckei A (1987) Free Radical Reactions in Medicine. Berlin: Springer-Verlag. $31-43$

Felgils F. (1975).Anthraquinone. Ascobic acid, Stop test in organic analysis. Elservier Press,Amserdam. Pp336-563

Friedewald WT, Levy RI and Fredrickson DS (1972) Estimation of the concentration of Lowdensity lipoprotein cholesterol in plasma, without use of the preparative Ultracentrifuge Clinical Chemistry, 18:499502

Giacco F and Brownlee M (2010) "Oxidative stress and diabetic complications," Circulation Research, 107(9): 1058-1070. neutralize different types of free radicals (Halliwell and Gulteridge, 2007).

\section{Conclusion}

The ethyl acetate leaf extract of Vitex simplicifolia is observed to have no hypolipidemic and antioxidant activity on alloxan induced diabetic Wistar rats.

Giugliano D, Ceriello A and Paolisso G, (1995).Diabetes mellitus, hypertension, and cardiovascular disease: which role for oxidative stress?" Metabolism, 44(3):363-368

Gomes E, Silva A an Oliveira M (2015) "Oxidants, antioxidants, and the beneficial roles of exercise-induced production of reactive species," Oxidative Medicine and Cellular Longevity, 201:32- 12

Good C,Kramer H and Somogy M (1993).Two methods for determination of liver glycogen content.J.Boil.Chem.100:48-45.

Halliwell B and Gutteridge J, (2007). Free Radicals in Biology and Medicine, Oxford University Press, New York, NY, USA, 4th edition.Pp 711-7.

International Diabetes Federation(IDF),(2015). Diabetes Atlas. 4th edn. The economicimpact of diabetes.http://www.diabetes atlas.org/cotent/economic impact of diabetes. Accessed on February 4, 2010.

Kingsley .C, Patrick I, Edidiong A. O and Orish E (2014) Evaluation of acute and sub-chronic toxicities of Vensestin Cleansers: a polyherbal supplement in female Wistar Albino rats, Journal of Applied Pharmaceutical Science; 4 (06): 074-078,

Lorke, D.A (1983). A new approach to practical acute toxicity testing.ArchToxico/ 54:275 - 87

Masiello, P,Broca, C,Gross R,Roye, M,Manteghetti, M,Hillare -Buys D,Novelli, M and Ribes, G (1998) Expiremental NIDDM:development of a new model in adult rats administered with streptozotocin nicotinamide.Diabetes 47(2):224-9

McCord JM and Fridovich I. (1969) Superoxide dismutase. An enzymic function for erythrocuprein (hemocuprein). $\mathrm{J}$ Biol Chem. 244(22):6049-6055 Med30(11):1191-212

Negre-Salvayre A, Salvayre R, Aug'e N, Pamplona R and Portero $M,(2009)$.Hyperglycemia and glycation in diabetic complications," Antioxidants and Redox Signaling, 11(12):3071-3109.

Oberley L, (1988). Free radicals and diabetes. Free Radical Biology in Medicine; 5:113-124

Ogbonnia SO, Odimegwu JI and Enwuru VN (2008). Evaluation of hypoglycemic and hypolipidemic effects of ethanolic extracts of Treculia africana Decne and Bryophyllum pinnatum Lam. and their mixture on streptozotocin (STZ) - induced diabetic rats. Afr. J. Biotechnol., 7(15):2535-2539. 
Bajopas Volume 10 Number 1 June, 2017

Okpe, O, Abdullahi, S A., Nkeonye, O, Ilechukwu C., Nweke,O and Ihuoma O. (2012). Hypoglycemic and Hypolipedimiceffects of aqueous and ethanolic leaf extracts of Vitex doniana in normoglycemic Albino rats. Global Advance Reaserch journal of Microbiology, 1(10)173-179.

Prasanna R, Sivakumar. V and Riyazullah. M. S (2012) Antidiabetic Potential of Aqueous and Ethanol Leaf Extracts of Vitex negundo. International Journal of Pharmacognosy and Phytochemical Research; 4(2); 38-40 rats. Afr. J. Biotechnol., 7(15):2535-2539.

Price KR, Johnson IT and Fenwick GR (1987) The chemistry and biological significance of saponins in food and feeding stufs. Critical Reviews in Food Science and Nutrition, 26: 27-133

Ravichandran V, Deivam S, Anbu1, and Reeta R (2014) Acute and sub-acute toxicity studies of ethanolic poly-herbal extract in mice. International Journal of Pharmacology \& Toxicology, 4(2): 80-87

Roe JH and Kuether CA (1943) The determination of ascorbic acid in whole blood and urine through the 2,4 - dinitrophenylhydrazine derivative of dehydroascorbic acid Journal of Biological Chemistry.147:399 - 407

Rotimi, SO, Olayiwola, I, Ademuyiwa, $\mathrm{O}$ and Adamson, I (2010). Inability of legumes to reverse diabetic-induced nephropathy in rats despite improvement in blood glucose and antioxidant status.J. Med. Food, 13:163-9.

Shulman, G.I., Rothman, D.L., Jue, T., Stein, P., Defronzo, R.A. and Shulman, R.G. (1990). Quantitation of muscle glycogen synthesis in normal subjects and subjects with noninsulin-dependent diabetes by nuclear magnetic resonance spectroscopy.N. Engl. J. Med. 322: 223 - 228.

Sobngwi, E, Mauvais-Jarvis F, Vexiau P and Gautier JF (2001). Diabetes in Africans: epidemiology and clinical specificities. Diabetes Metab (Paris), 27: 628-34.

Sofowora, A. (1993).Medicinal Plants and Traditional Medicine in Africa.2ndEdn.,Spectrum Books,Nigeria,ISBN13:9789782462190,pp142-144 